\section{ELECTRICAL ANALOGIES WITH NATURAL PHENOMENA ${ }^{1}$}

II.

POLAR AURORA.-The experiments of De la Rive

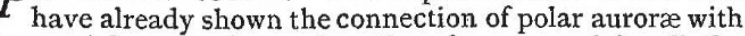
terrestrial magnetism; but they do not explain all the circumstances which accompany auroræ. In M. Planté's experiments the electric current, in presence of aqueous vapour, yields a series of phenomena altogether analogous to the various phases of yolar auroræ.
If the positive electrode of the secondary battery is brought into contact with the sides of a vessel of salt water, we observe, according to the distance of the film from the liquid, either a corona formed of luminous particles arranged in a circle around the electrode (Fig. 8), an arc bordered with a fringe of brilliant rays (Fig. 9), or a sinuous line which rapidly folds and refolds on itself (Fig. IO). This undulatory movement, in particular, forms a complete analogy with what has been compared in auroræ to the undulations of a serpent, or to those of drapery agitated by the wind. The rustling noise accompanying the ex-
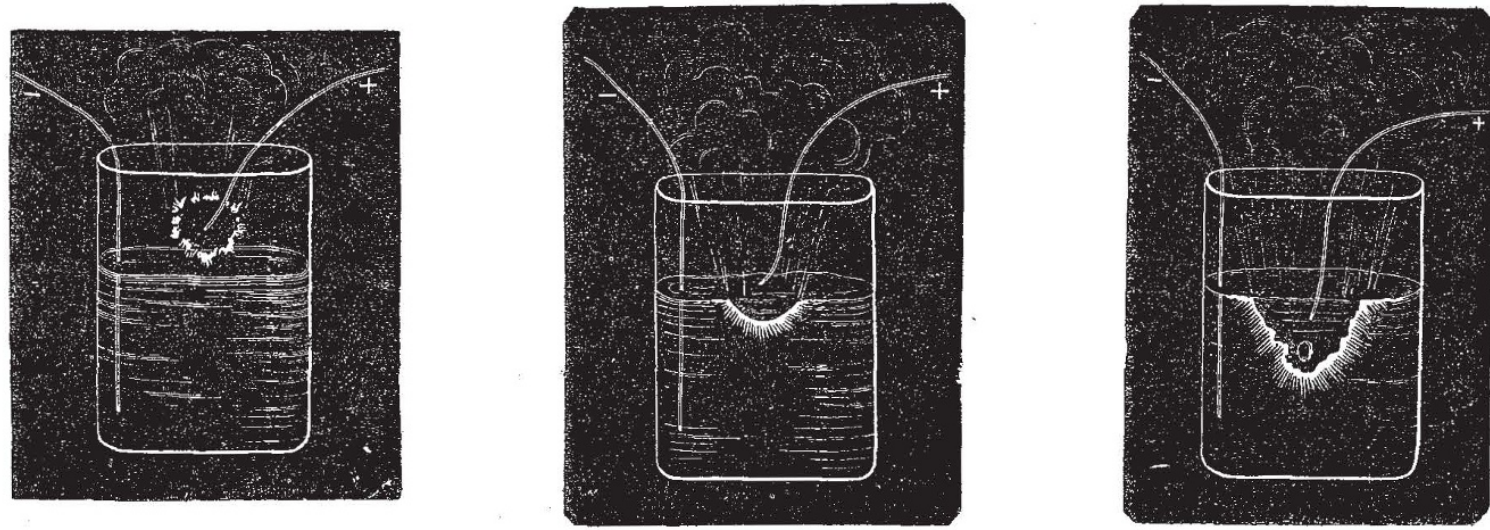

Figs. 8, 9, ro.-Coronas and luminous arcs.

periments is analogous to that sometimes accompanying auroræ; it is caused by the luminous electric discharge penetrating the moisture. As in auroræ, magnetic perturbations are produced by bringing a needle near the circuit, the deviation increasing with the development of the arch. Auroræ are produced by positive electricity; the negative electrode produces nothing similar.

Globular Lightning.-To study the effects produced

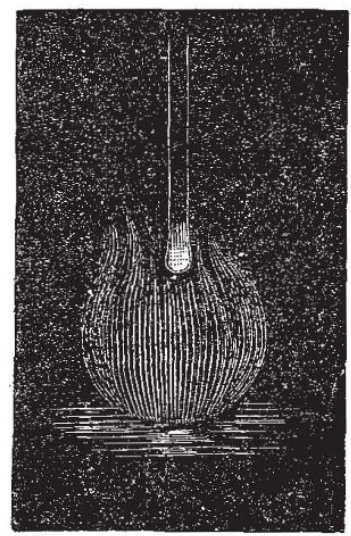

FIG. II.-Flame produced over distilled water by an electric current of high tension.

on distilled water, M. Plante increased the tension of the current, combining twenty secondary batteries, composed each of forty couples, and forming a total of 800 secondary couples, whose current of discharge was nearly equal to that of $\mathrm{I}, 200$ Bunsen elements.

When the current of this combination of batteries is made to act on distilled water, he finds, first, in much greater intensity, the effects already observed by Grove, by means of 500 elements of his nitric acid pile. The $x$ Contiuued from p. 229 . positive electrode being inserted in the distilled water, he obtains, by approaching the negative platinum wire to the surface of the water, and immediately raising it; a yellow flame, almost spherical, of about two centimetres in diameter (Fig. II). The platinum wire, two millimetres in diameter, melts; the flame is formed by the rarefied incandescent air, by the vapour of the metal of the electrode, and by the elements of the vapour of water; spectral analysis shows clearly the presence of hydrogen.

If, to avoid the fusion of the metal, we diminish the intensity of the current by interposing a column of water in the circuit, the spark appears under the very compact form of a small globe of fire from eight to ten millimetres in diameter (Fig. I2). On raising the electrode a little more, this globe takes an ovoid form; luminous blue points, whose number varies continually, arranged in concentric circles, appear at the surface of the water (Fig. 13). Rays of the same colour soon issue from the centre and join these points (Fig. I4). At intervals the rays take a gyratory movement, now in one direction, now in another, describing spirals (Figs. I5 and I6). Sometimes the points and the rays disappear all on one side, and varied curves, formed by the movement of those which remain, are figured on the surface of the liquid. Finally, when the speed of the gyratory movement increases, all the rays vanish, and only blue concentric rings are seen (Fig. 17). The rings are found to be the last term of these transformations which are very curious to follow with the naked eye or with a telescope, and constitute a veritable electric kaleidoscope.

The production of these figures is explained by the great mobility of the arcs or luminous threads which compose the ovoid light, formed between the water and the electrode. On examining with care this particular form of spark, he finds that it is, in reality, a sort of voltaic brush discharge, analogous to the brush discharge of static electricity, but more dense on account of the greater quantity of electricity in play. These luminous threads being in a state of continual agitation, the points at which they encounter the surface of the liquid are constantly displaced, and form the rays observed. Their gyratory movement 
proceeds from the reaction due to the flowing of the electric flux. As to the rings, they are formed in a visible manner, under the eye of the observer, by the more and more rapid movement of the blue points, and by the persistence of the impression upon the retina.

When the metallic electrode is positive and the distilled water negative, the spark still assumes externally an ovoid form; but the middle is traversed by a cone of violet light. When we employ two metallic electrodes we obtain a luminous spheroid, the interior of which is traversed by a brilliant line. This appearance corresponds to the spark, and the aureole of the spark seen in the discharges of an induction coil; only here the aureole occupies more space, in consequence still of the greater quantity of electricity. In fact, if we much increase the length of the column of water interposed, we do not obtain more than an arc or a straight line.

M. Planté therefore thinks globular lightning may result from an abundant flow of electricity in the dynamic state, in which quantity is joined to tension. The particular

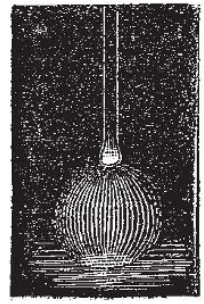

FrG. 12.-Globular spark produced over distilled water by an electric current of high tension.

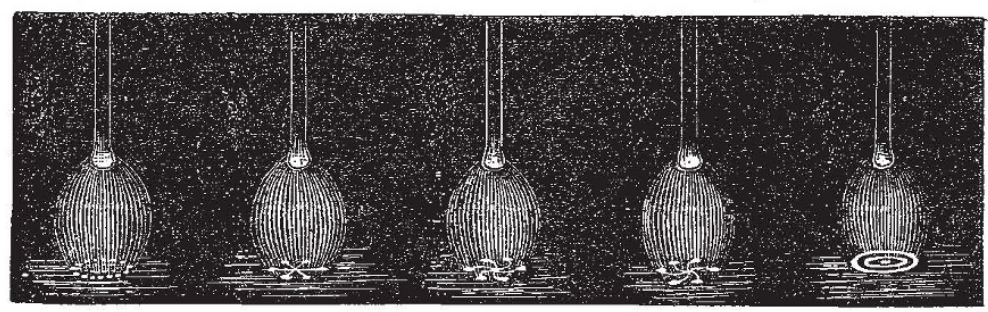

FIGS. 13:0 17.-Cvoid sparks ind luminous figures produced over distilled water by an electric current of high tension. case where globes of lightning present slow movements or times of stoppage, is explained by the movement or the repose of the column of moist air strongly electrified and invisible, which serves as electrode. To imitate this effect it is sufficient, in one of the preceding experiments, to make the electrode oscillate, it being previously suspended under the form of a long pendulum above a basin full of water or a metallic surface, and to mask by a screen its lower extremity. We then see a little ball of fire move above the water or the conducting surface, and thus reproduce all the appearances of the natural phenomenon.

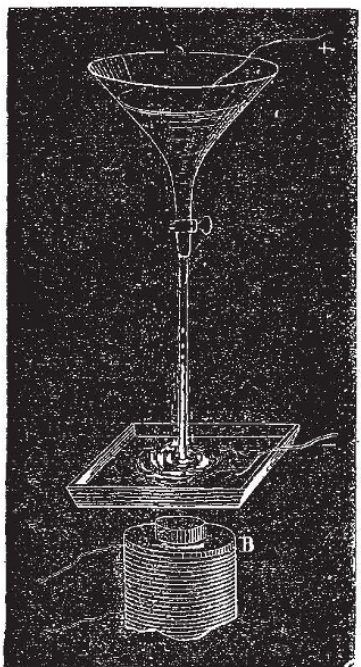

Fig, 18,-Experiment reproducing the effect of waterspouts

Watersponts.-Cause a narrow stream of salt-water to flow from a funnel provided with a cock communicating with the positive pole of a battery of 400 secondary couples; the liquid is received in a basin containing the negative wire and below which is an electro-magnet (Fig. 18). As soon as the voltaic circuit is closed the stream appears furrowed with bright lines at its upper part and traversed by a luminous thread at its lower part. Sparks, illuminated aqueous globules, play with a rustling noise at its extremity, vapour is disengaged, and the liquid which surrounds the bottom of the stream takes a gyratory movement in the opposite direction to that of the hands of a watch if the pole of the electro-magnet is north, and in the same direction as the hands if this pole is south. The movement is rendered visible by light bodies spread over the surface of the water. If we contract the stream so as to avoid all solution of continuity at its lower part, the electric and luminous signs disappear almost entirely. "The liquid is, nevertheless, heated, as is shown by a light vapour, and the gyratary movement is yet more pronounced and rapid. On extending the stream anew the electric manifestations re-appear as before.

This experiment reproduces the principal effects of waterspouts, the rustling which proceeds from them, the

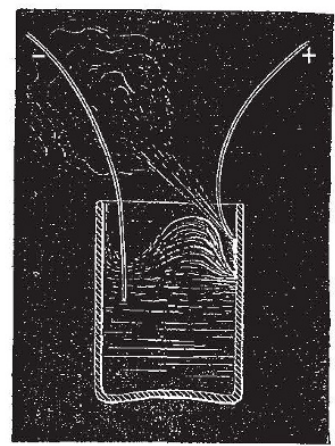

Fif. 19.-Electric bore.

mist which is formed around them, the flashes of light which furrow them, the globes of fire which sometimes appear at their extremities--in such a way that, according to M. Planté; these meteors may be compared to electrodes of liquid or of vapour, from which escape to the earth or the sea the powerful electric currents of stormclouds; and if no thunder follows it is because the conductor accompanies them to the ground, and there is in this case no proper electric discharge, no more than under the precediny conditions.

The very formation of waterspouts, or the descent of these cloudy appendages towards the ground, has been connected by Brisson and Peltier with an electrostatic attraction between the clouds and the earth. We may add to this very natural attractive force an action of transport, 
of which dynamic electricity presents numerous examples, and which tends to facilitate the flow of water from an electrified cloud. The agitation of the liquid, the boiling of the waters at the point where these meteors encounter the surface of the sea, are explained not only by the descending movement itself, but also by the action of the electric current, which may repel or raise liquid masses like a breeze or an impetuous wind. If we support, in

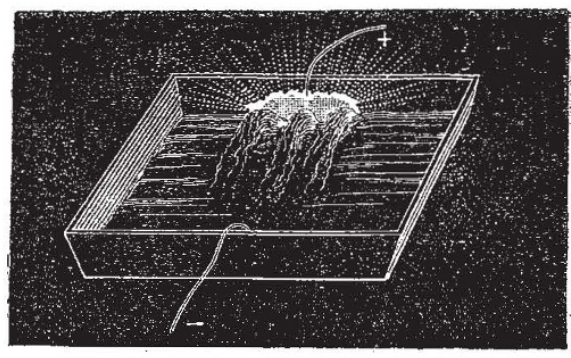

FIG. 20.-Electric bore or formation of iquid waves by the flow of a powerful current of dynamic electricity.

fact, the positive electrode against the sides of the vessel of salt-water communicating with the negative pole, we observe, besides the luminous streaks and jets abounding in vapour, a violent whirling of the liquid forming a sort of electric bore, which raises the water to the height of $\mathrm{I}_{\frac{1}{2}}$ centimetre above its level (Fig. 19). When the current meets at certain points inequalities of resistance, it is divided and gives rise to several aqueous hillocks, as seen in Fig. 20.

\section{ON COMPASS ADFUSTMENT IN IRON SHIPS AND ON NAVIGATIONAL SOUNDINGS 1}

IV.-On a Navigational Sounaing Machine.

THE machine before you is designed for the purpose of obtaining soundings from a ship running at full speed in water of any depth not exceeding 100 or 150 fathoms. The difficulties to be overcome are twofold : first, to get the lead or sinker to the bottom; and, secondly, to get sure evidence as to the depth to which it has gone down. For practical navigation a third diffculty must also be met, and that is to bring the sinker up again ; for, although in deep-sea surveys in water of more than 3,000 fathoms' depth it is advisable, even when piancforte wire is used, to leave the thirty or forty pounds' sinker at the bottom, and bring back only the wire with attached instruments, it would never do in practical navigation to throw away a sinker every time a cast is taken, and the loss of a sinker, whether with or without any portion of the line, ought to be a rare occurrence in many casts. The first and third of these difficulties seem insuperable-at all events they have not bitherto been overcomewith hemp rope for the sounding-line; except fur very moderate depths, and for speeds much under the full speed of a modern fast steamer. It may indeed be said to be a practical impossibility to take a sounding in twenty fathoms from a ship running at sixteen knots with the best and best-managed ordinary deepsea lead. Taking advantage of the great strength and the small and smooth area for resistance to motion through the water, presented by pianoforte wire, I have succeeded in overcoming all these difficulties; and with such a sounding machine as that before you the White Star liner Britannic (Messrs. Ismay, Imrie, and Co., Liverpool) now takes soundings regularly, running at sixteen knots over the Banks of Newfoundland and in the English and Irish Channels in depths sometimes as much as 130 fathoms. In this ship, perhaps the fastest ocean-going steamer in existence, the sounding machine was carefully tried for several voyages in the hands of Capt. Thompson, who succeeded perfectly in using it to advantage; and under him it was finally introduced into the service of the White Star Line.

- Report of paper read to the Royal United Service Institution, February 4, by sir Wm. Thomson, LL.D., F.R.S., P.R.S.E., Professor of Natural Philosóphy in the University of Glasgow, and Fellow of St. Peter's College, Cambridge. Kevised by the Author. [Ihe Council of the R.U.S.I. have kindly permitted us to publish Sir W. Thomson's paper in advance, and have granted us the use of the illustrations. - Ev.] Continued from p. 354 .
The steel wire which I use weighs nearly $I_{\frac{1}{2}}$ lbs. per 100 fathoms, and bears when fresh, from 230 to $240 \mathrm{lbs}$. without breaking; its circumference is only 03 of an inch. By carefully keeping it always, when out of use, under lime water in the galvanised iron tank prepared for the purpose, which you see before you, it is preserved quite fiee from rust, and, accidents excepted, this sounding line might outlive the iron plates and frames of the ship. If the sinker gets jammed in a cleft of rock at the bottom, or against the side of a boulder, the wire is inevitably lost. Such an accident must obviously be very rare indeed, and there does not seem to be any other kind of accident which is altogether inevitable by care in the use of the instrument. The main care in respecc to avoidance of breakage of the wire may be stated in three words-beware of kinks. A certain amount of what I may call internal molecular wear and tear will probably occur through the wire bending round the iron guard rod which you see in the after part of the instrument, when, in hauling in, the wire does not lead fair aft in the plane of the wheel, as is often the case even with very careful steering of the ship, but from all we know of the elastic properties of metals, it seems that thousands of casts might be taken with the same wire before it would be sensibly weakened by internal molecular friction. Practice has altogether confirmed these theoretical anticipations so far as one year of experience can go. My sounding machine has been in regular use in charge of Captains Munro and Hedderwick in the Anchor liners Anchoria and Devonia (Messrs. Henderson Brothers, Glasgow) for eleven months and seven months respectively, and in neither ship has a fathom o wire been lost hitherto, though soundings have been taken at all hours of day and night, at full speed, in depths sometimes as great as I20 fathoms. No break not explicable by a kink in the wire has hitherto taken place in any ship provided with the sounding machine. That it will bear much rough usage is well illustrated by one incident which happened in a cast taken from the Devonia running at thirteen knots. The sinker in falling from the wheel into the water accidentally fell between the rudder chain and the ship, and fifty fatboms or so had gone out before it was noticed that the wire was running down vertically from the wheel instead of nearly horizontally as it ought to have been by that time. The handles were immediately applied to the sounding wheel, and it was turned round to haul in without reducing the speed of the ship. Though the wire was bent almost at right angles round the chain until it was nearly all in, it was all got safely on board, as was also the cod-line with attached depth gauge, and the sinker at the end of it.

When soundings are being taken every hour or more frequently (as in the case ot a ship feeling her way up channel from the 100 fathom line when the position is not known with sufficient certainty by sights and chronometers) the sounding wheel should be kept on its bearings in position; with the cod-line, depth gauge, and sinker, all bent on and ready for use. But in all other cases the wheel should be kept in its tank under lime water, and the cod-line with sinker and depth gauge attached should be kept at hand in a convenient place near the stand of the machine, which should be always fixed in position ready for use. With such arrangements, and methodical practice, as part of regular naval drill in the use of the sounding machine, one minute of time should suffice to take the sounding wheel out of its tank, place it on its bearings, adjust the brake cord, bend on the cod-line, and be quite ready for a cast. When the machine is to be shown to an inspecting officer the wheel ought to be in its tank of lime water when he asks to see a cast. It should be carefully noticed that the ring at the end of the wire is securely lashed by small cord to the hole provided for it in the ring of the wheel whenever the cod-line is unbent from the ring. If the wire and ring are allowed at any time to knock about slack on the wheel when the wheel is being moved to be set up for use or to be replaced under the lime-water there is a liability to some part of the wire getting a turn which may be pulled into a kink. One accident, at least, has happened in this way: the sinker dropped off carrying the cod-line and ring with it just as it was being let down trom the taffrail for a cast. If the sinker had weighed $400 \mathrm{lbs}^{1}{ }^{1}$ it could not have broken the double wire next the ring without a kink.

A description of the machine and rules for its use are given in the accompanying printed paper of instructions, to which I have only now to add a few words regarding the depth gauge. Erichsen's self-registering sounding lead (patented in 1836), depending on the compression of air, might be used with my machine, but the simpler form before you is preferable as beinir ${ }^{x}$ It weighs $22 \mathrm{lbs}$. 